\title{
High miR-449b expression in prostate cancer is associated with biochemical recurrence after radical prostatectomy
}

Martin Mørck Mortensen ${ }^{1,2}$, Søren Høyer ${ }^{3}$, Torben Falck Ørntoft ${ }^{1}$, Karina Dalsgaard Sørensen ${ }^{1}$, Lars Dyrskjøt ${ }^{1 *}$ and Michael Borre ${ }^{2 \dagger}$

\begin{abstract}
Background: Prostate cancer is one of the leading causes of cancer death amongst men in economically advanced countries. The disease is characterized by a greatly varying clinical course, where some patients harbor non- or slowly-progressive disease, others highly aggressive disease. There is a great lack of markers to differentiate between aggressive and indolent disease. Markers that could help to identify patients needing curative treatment while sparing those who do not.

Methods: MicroRNA profiling of 672 microRNAs using multiplex RT-qPCR was performed using 36 prostate cancer samples to evaluate the association of microRNAs and biochemical recurrence after radical prostatectomy.

Results: Among 31 microRNAs associated with recurrence, we identified miR-449b, which was further validated in an independent cohort of 163 radical prostatectomy patients. Patients expressing miR-449b had a significantly higher risk of recurrence $(H R=1.57 ; p=0.028)$, and miR-449b was shown to be an independent predictor of recurrence after prostatectomy $(H R=1.9 ; p=0.003)$ when modeled with known risk factors of recurrent disease in multivariate analysis.
\end{abstract}

Conclusion: High miR-449b expression was shown to be an independent predictor of biochemical recurrence after radical prostatectomy.

Keywords: Prostate cancer, microRNA, miR-449, Biomarker, Biochemical recurrence, Prostatectomy

\section{Background}

There is a great unmet need for better diagnostic as well as predictive tools in prostate cancer (PC) needed for discerning aggressive $\mathrm{PC}$ from indolent PC. Although this disease has the second highest cancer mortality amongst men, approximately 250,000 worldwide [1]. The prevalence hereof, as indicated by autopsy studies, is even higher and reported as being up to 12$54 \%$ of all men aged over 50 years [2]. Early diagnosis is imperative since curative treatment is only possible in non-metastatic PC. This has led to the widespread use of screening for PC using Prostate Specific antigen

\footnotetext{
*Correspondence: lars@clin.au.dk

${ }^{\dagger}$ Equal contributors

${ }^{1}$ Department of Molecular Medicine, Aarhus University Hospital, Brendstrupgaardsvej 100, 8200 Aarhus N, Denmark

Full list of author information is available at the end of the article
}

(PSA) testing, but since the prevalence of non-lethal, non-progressive $\mathrm{PC}$ is very high, screening leads to a substantial risk of overtreatment [3]. Biomarkers associated with aggressive PC have the potential of improving existing prediction models for identifying patients with aggressive disease and thus aid patients and physicians in deciding between curative treatment and active surveillance [4]. Furthermore, biomarkers associated with aggressive disease could be used for monitoring patients in active surveillance and be used as a trigger for offering curative treatment if the biomarker level changes [5].

In brief, microRNAs are small 18 to 25 nucleotide RNA molecules that function as regulators of gene expression through incorporation into the RNA-induced silencing complex (RISC). The incorporated microRNA binds to mRNA sequences with complementary to the microRNA. Following binding, the Argonaute (Ago) 
protein also incorporated in RISC cleaves the mRNA strand and thus causes degradation of the target transcript and thereby silences the gene [6]. Through this post transcriptional process miRNA can influence gene expression and thus regulate various biological processes. Since the key biological differences between cancer cells and their normal counterparts are the initiation and utilization of cellular processes like increased proliferation, immortalization and invasive properties, altering gene expression is central in tumorigenesis [7]. Previous studies have shown that miRNA can be central in orchestrating the altered gene expression necessary for the cell to undergo transformation to a cancer cell [6]. As each miRNA can have many different putative target mRNAs, a miRNA can essentially be the central tumorigenic factor [8] or it can function through inhibiting mRNAs that in turn function as either oncogenes or tumor suppressors $[9,10]$.

miRNAs are generally more stable and easier to measure in biological material where degradation is an issue compared to mRNA [11,12]. Therefore, miRNAs may prove to be good biomarkers for diagnosis as well as for monitoring PC. It has been shown in several studies that miRNA can be assayed in blood from PC patients and that diagnostic miRNAs can be identified $[13,14]$.

Several studies have shown that miRNAs are aberrantly expressed in PC and several specific miRNAs have been implicated in PC development [15-19]. While most studies of miRNA in PC have focused on miRNAs differentially expressed between normal and cancerous prostate tissue, only a few studies have focused on miRNA expression associated with aggressive disease. A number of different surrogate end-points for aggressive PC have been used in the studies like presence of perineural invasion [20], Gleason grade [20,21], extra prostatic growth [16] and risk of recurrence [22]. These differences in end-points, and the limited power of some studies due to few analyzed samples, are probably the main reasons that reproducing results is difficult, as described by Coppola et al. [23].

Here we performed microRNA profiling using multiplex qPCR on laser micro dissected material from 36 PC patients to identify microRNAs associated with recurrence after radical prostatectomy $(\mathrm{RP})$. We validated the association with recurrence of the top ranked miR-449b in an independent cohort of patients using singleplex RT-qPCR.

\section{Methods}

\section{Ethics statement}

The study was approved by the Central Denmark Region Committees on Biomedical Research Ethics case number 2002-41-2640. Informed written consent was obtained from all patients.

\section{Clinical samples}

Samples for this study were provided by the Aarhus prostate cancer project consisting of all patients undergoing radical prostatectomy at the Dept. of Urology Aarhus University Hospital from 1995 to present day. Samples included in the study were from 2003 to 2007. Clinical data were collected prospectively and recurrence status for all patients in the study was updated prior to inclusion in the study. The prostatectomy specimens were examined by an experienced uro-genitopathologist assessing pathological stage (pT) and tumor differentiation scored according to Gleason. No re-review of the Gleason grade was performed. Serum PSA was measured prior to surgery by automated immunoassay using DPC Total PSA Immulite and expressed in ng/mL. Clinical follow up after surgery was conducted by PSA measurements at 3, 6, and 12 months postoperatively and thereafter biannually. Subsequent biochemical failure was defined as two consecutive measurements of PSA $>0.2 \mathrm{ng} / \mathrm{mL}$. Needle biopsies were taken from the surgical prostatectomy specimen and immediately snap frozen.

For the validation phase, samples cores $1.5 \mathrm{~mm}$ in diameter were taken from formalin fixed paraffin embedded (FFPE) radical prostatectomy specimens. The patient cohort [24,25] and sampling protocol for RNA extraction have previously been described. All clinical information from the patient cohort was updated regarding recurrence status prior to inclusion in the current study. Patients with at least 4 years recurrence free survival and patients with proven biochemical recurrence were included.

\section{Laser micro dissection and RNA extraction}

Survey slides of the biopsies were examined and the carcinoma cells identified. Since all material was reevaluated by an experienced uro-genito-pathologist to ensure that only tumor tissue was included. Subsequently, slides were stained with cresyl-violet $1 \%$ and the carcinoma cells were laser micro dissected using the PALM laser microbeam system. RNA extraction was performed using RNeasy ${ }^{\oplus}$ Micro kit from Qiagen (Germany). Flow through from the RNA extraction contains RNA fragments that are shorter than 120 nucleotides in length, thus the total microRNA fraction was contained within the flow through. A second microRNA extraction was performed on the flow through with RNeasy micro kit optimized for extracting micro RNAs.

RNA extraction from FFPE tissue was performed using RNeasy ${ }^{\circ}$ FFPE Kit (Qiagen Germany) in which the total RNA fraction contains RNA fragments down to 18 nucleotides in length. RNA260/280 ratio and the RNA concentration of each sample was measured using NanoDrop (Tecan). 


\section{miRNA expression profiling}

miRNA expression profiling was carried out using Taqman Low Density Array Human microRNA A + B Cards v3.0 (Micro fluid cards, Applied Biosystems, Foster City, USA). Equal volumes of flow-through were used as input material, and the miRNA was reverse transcribed using Megaplex ${ }^{\mathrm{tm}}$ pool A and B (Applied Biosystems) followed by pre amplification. The cDNA pool was applied to the multiplex array cards and the experiment was run on the ABI 7900 HT platform using cycling conditions as provided by the manufacturer. Normalization of results was done using RQ Manager (Applied Biosystems). A common threshold was established across all array cards for each miRNA, expression levels were normalized to MammU6 and average delta-Ct was used in downstream analyses. miRNA expression data is available at GEO (NCBI) with series accession no. GSE62610.

A total of $350 \mathrm{ng}$ total RNA was reverse transcribed using Megaplex ${ }^{\mathrm{tm}}$ pool A (Applied Biosystems) followed by pre-amplification according to manufacturer protocol for miRNA expression profiling in FFPE tissue. We performed singleplex RT-PCR amplifications for each of the candidate miRNAs selected for validation using Taq-man probes with the assay ids: 001129, 002255, 002306, 002295, 001608 and 001960, with MammU6 as reference. All samples were measured in triplicates and a no template and a no RT control were included on all plates.

\section{Statistical analyses}

Statistical analyses were performed using STATA version 10.1 (StataCorp, College Station TX, USA). P-values < 0.05 were considered statistically significant. Ranking of the miRNAs was done using Mann-Whitney rank-sum test in the screening study. Median fold change was given by the relation between the median expression level in the recurrent group versus the level in the nonrecurrent group. Association with biochemical recurrence after radical prostatectomy was analyzed using univariate and multivariate Cox regression analysis in the validation study. For each variable in the Cox regression analyses the proportional hazard assumption was verified by log-log survival curves. The prediction accuracy was estimated using Harrell c's concordance index. Pathological T-stage was dichotomized in localized and extra prostatic disease. Gleason score was grouped in three categories containing scores $5-6,7$, and $8-10$ respectively. Preoperative PSA levels were grouped according to the D'Amico classification with $<10 \mathrm{ng} / \mathrm{ml}, 10$ to $20 \mathrm{ng} / \mathrm{ml}$ and $>20 \mathrm{ng} / \mathrm{ml}$.

\section{Results}

In total, 36 tumor samples were laser micro dissected and 672 miRNAs profiled using multiplex RT-qPCR to identify novel miRNAs associated with recurrence after
RP. Sixty \% of the patients had suffered recurrence and the median follow-up of those without recurrence was 66 months (range 31-80 months). Clinical and histopathological information is listed in Table 1 . Initially the miRNA expression data was filtered to exclude miRNAs with no detection above background in any of the samples, leaving 536 miRNAs for further analysis. A total of $235(44 \%)$ miRNAs were detected in all samples in the filtered dataset.

\section{Delineation of key miRNA transcripts associated with outcome}

We delineated miRNAs that showed significant association with recurrence. In total, 28 miRNAs were found to be significantly up regulated and 3 miRNAs were significantly down regulated in tumors from patients with recurrence ( $\mathrm{p}<0.05$ Mann-Whitney), compared to tumors from patients without recurrence. Median fold changes between recurrent and non-recurrent cases ranged from 1.18 to 16 in the up regulated miRNAs and 4.2 for the down regulated miR-24-1-5p (Table 2). Top ranked up regulated miRNA was miR-449b $(\mathrm{p}=0.0061$, Mann-Whitney) with a 2.8 times higher expression in patients with recurrent disease compared with patients with non-recurrent disease.

Table 1 Clinical and histopathological characteristics of the screening cohort and the validation cohort

\begin{tabular}{|c|c|c|}
\hline Clinical variable & $\begin{array}{l}\text { Screening } \\
\text { cohort (FF) }\end{array}$ & $\begin{array}{c}\text { Validation } \\
\text { cohort (FFPE) }\end{array}$ \\
\hline Total number of cancer samples & 36 & 163 \\
\hline Age median(range) Years & $63(46-71)$ & $62(48-72)$ \\
\hline \multicolumn{3}{|l|}{ Gleason grade } \\
\hline Low (5-6) & $17(47 \%)$ & $60(37 \%)$ \\
\hline Intermediate (7) & $15(42 \%)$ & $85(52 \%)$ \\
\hline High $(8-10)$ & $4(11 \%)$ & $18(11 \%)$ \\
\hline \multicolumn{3}{|l|}{ Pathological stage } \\
\hline $\mathrm{T} 2 \mathrm{a}-\mathrm{c}$ & $19(53 \%)$ & $96(59 \%)$ \\
\hline $\mathrm{T} 3 \mathrm{a}-\mathrm{b}$ & $17(47 \%)$ & $67(41 \%)$ \\
\hline Time to recurrence (range) Months & $15.6(1-74)$ & $24(3-122)$ \\
\hline Follow up non-recurrent cases Months & $66(31-80)$ & $65(48-114)$ \\
\hline \multicolumn{3}{|l|}{ Recurrence } \\
\hline Yes & $22(61 \%)$ & $96(59 \%)$ \\
\hline No & 14 (39\%) & 67 (41\%) \\
\hline \multicolumn{3}{|l|}{ Margin status } \\
\hline Positive & $16(44 \%)$ & $45(28 \%)$ \\
\hline Negative & $20(56 \%)$ & 118 (72\%) \\
\hline Pre-operative PSA (range) & $16.0(5.3-42.5)$ & $13.2(2.1-64.5)$ \\
\hline
\end{tabular}

FF: fresh frozen tumors. FFPE: formalin fixed paraffin embedded tumors. 
Table 2 miRNAs significantly associated with recurrence

\begin{tabular}{|c|c|c|c|c|}
\hline miRNA & $\begin{array}{c}\text { Rank sum } \\
\text { p-value }\end{array}$ & Reference & $\begin{array}{c}\text { Median } \\
\text { fold change }\end{array}$ & $\begin{array}{c}\text { Selected for } \\
\text { validation }\end{array}$ \\
\hline \multicolumn{5}{|c|}{ Up regulated in recurrent cases } \\
\hline mir449b & 0.0061 & {$[16,22]$} & 2.80 & $x$ \\
\hline mir137 & 0.0069 & & 14.88 & $x$ \\
\hline mir30e-3p & 0.0195 & & 1.59 & \\
\hline mir339-3p & 0.0195 & & 1.77 & \\
\hline $\operatorname{mir} 362-5 p$ & 0.0195 & & 2.38 & \\
\hline mir630 & 0.0202 & & 1.00 & \\
\hline mir149 & 0.0212 & & 1.98 & $x$ \\
\hline $\operatorname{mir} 342-3 p$ & 0.0231 & & 1.75 & \\
\hline mir30a-3p & 0.0231 & & 1.63 & \\
\hline mir301b & 0.0252 & & 1.98 & \\
\hline mir182 & 0.0252 & & 1.83 & \\
\hline mir484 & 0.0252 & [16] & 1.71 & \\
\hline mir126 & 0.0252 & [20] & 2.34 & \\
\hline mir223 & 0.0297 & & 2.01 & $x$ \\
\hline mir636 & 0.0297 & & 2.23 & \\
\hline mir615-3p & 0.0315 & & $\mathrm{Na}$ & $x$ \\
\hline mir622 & 0.0335 & & 5.69 & \\
\hline $\operatorname{mir} 548 c-3 p$ & 0.0339 & & $\mathrm{Na}$ & \\
\hline mir197 & 0.0378 & & 1.70 & \\
\hline mir616-5p & 0.042 & & 2.16 & \\
\hline mir367 & 0.0426 & & 3.67 & \\
\hline mir214 & 0.0442 & & 2.10 & $x$ \\
\hline $\operatorname{mir} 125 a-5 p$ & 0.0442 & {$[20]$} & 1.34 & \\
\hline mir32 & 0.0442 & & 1.56 & \\
\hline mir566 & 0.0449 & & $\mathrm{Na}$. & \\
\hline $\operatorname{mir} 500^{*}$ & 0.0461 & & 5.22 & \\
\hline mir10a & 0.0478 & {$[20]$} & 2.06 & \\
\hline mir10b & 0.0478 & {$[20,22]$} & 1.94 & \\
\hline \multicolumn{5}{|c|}{ Down regulated in recurrent cases } \\
\hline mir24-1* & 0.0298 & & 3.43 & \\
\hline mir154 & 0.0353 & [19] & na. & \\
\hline mir873 & 0.0406 & & na. & \\
\hline
\end{tabular}

\section{Validation in independent cohort}

No miRNAs were significantly associated with recurrence when using conservative Bonferroni correction for multiple testing corrections - likely due to the small initial patient cohort. To compensate for this we performed an independent validation of the most significant miRNAs. Initially we selected a subset of 40 patients (20 recurrent and 20 non-recurrent patients) to investigate candidate miRNAs before testing the miRNAs using the whole cohort. Criteria for selecting miRNAs for validation were the $\mathrm{p}$-value in rank-sum test, fold change, biological function determined in the literature, and finally for technical reasons that the assay was included in the Megaplex pool A used for cDNA synthesis and preamplification. Based on these criteria, six miRNAs were selected for validation: miR-449b, miR-137, miR-149, miR-214, miR-223 and miR-615-3p. We found miR-449b expression to be associated with recurrence status in the 40 patients $\left(\mathrm{p}=0.017, \mathrm{Chi}^{2}\right.$-test). MiR-137 and miR-615$3 \mathrm{p}$ failed qPCR amplification, and there were no significant association between expression level of the miRNA and recurrence status for the rest (data not shown). Consequently, only miR-449b was measured in the entire validation cohort.

The entire validation cohort consisted of RNA samples extracted from FFPE tissue samples originating from 163 patients who underwent radical prostatectomy. Clinical characteristics of the validation cohort are summarized in Table 1 . Of the 163 samples, 78 (48\%) of the samples had detectable miR-449b expression above background. We found a significant association between miR-449b expression and PSA group ( $\mathrm{p}=0.02$; chi2), but no association with other clinical variables as shown in Table 3. Using univariate Cox regression analysis, we found that expression of miR-449b was significantly associated with the risk of recurrence after $R P(H R=1.57$, $\mathrm{p}=0.027)$. This correlation was also observed from Kaplan-Meyer survival estimates (Figure 1). In multivariate

\begin{tabular}{|c|c|c|c|}
\hline Clinical variable & $\begin{array}{c}\mathrm{Chi}^{2} \text {-test } \\
\mathrm{P} \text {-value }\end{array}$ & $\begin{array}{c}\text { miR-449b } \\
\text { expression }\end{array}$ & $\begin{array}{c}\text { No } \\
\text { miR-449b } \\
\text { expression }\end{array}$ \\
\hline Total number of cancer samples & & 78 & 85 \\
\hline Gleason grade & 0.27 & & \\
\hline Low (5-6) & & 27 & 33 \\
\hline Intermediate (7) & & 45 & 40 \\
\hline High (8-10) & & 6 & 12 \\
\hline Pathological stage & 0.73 & & \\
\hline T2a-c & & 47 & 49 \\
\hline T3a-b & & 31 & 36 \\
\hline Pre-operative PSA & 0.02 & & \\
\hline $0-10 \mathrm{ng} / \mathrm{ml}$ & & 22 & 27 \\
\hline $10-20 \mathrm{ng} / \mathrm{ml}$ & & 44 & 31 \\
\hline $20-\mathrm{ng} / \mathrm{ml}$ & & 12 & 27 \\
\hline Recurrence & 0.05 & & \\
\hline Yes & & 26 & 41 \\
\hline No & & 52 & 44 \\
\hline Margin status & 0.21 & & \\
\hline Negative & & 54 & 64 \\
\hline Positive & & 24 & 19 \\
\hline
\end{tabular}




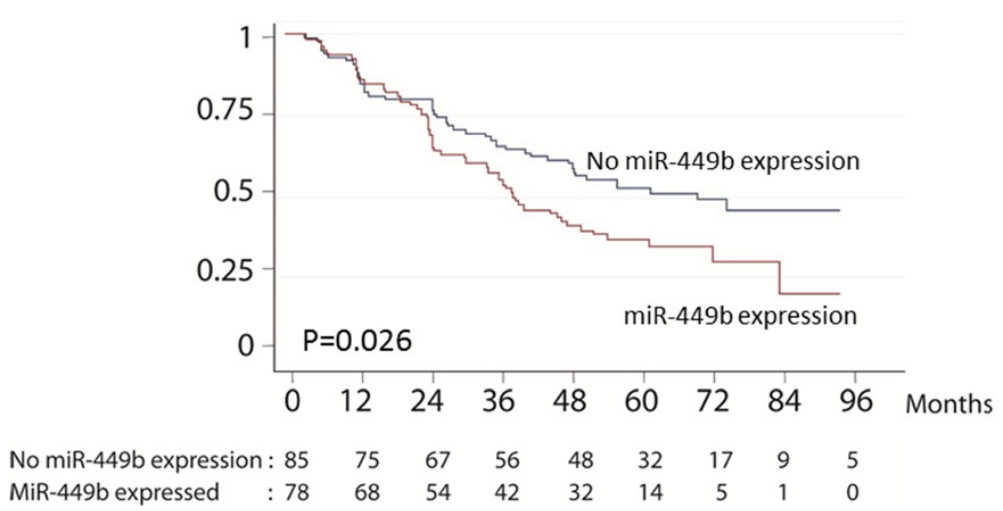

Figure 1 Kaplan-Meier survival curves showing recurrence free survival as function of miR-449b expression in the validation cohort.

Cox regression analysis modeled with Gleason grade, pathological t-stage, margin status, age and preoperative PSA, we found that miR-449b expression was an independent predictor of recurrence after $\mathrm{RP}(\mathrm{HR}=$ $1.90, \mathrm{p}=0.003$ ) (Table 4). The overall prediction accuracy determined by the Harrell's $\mathrm{C}$ index of the multivariate model containing clinical variables alone was 0.69 , compared to 0.71 when $\mathrm{miR}-449 \mathrm{~b}$ expression status was added to the model.

\section{Discussion}

Our study revealed 31 miRNAs differentially expressed between patients suffering recurrence and patients with no recurrence. Furthermore the top ranked miR$449 \mathrm{~b}$ was successfully validated in an independent cohort of 163 patients using RT-qPCR and found to be an independent predictor of biochemical recurrence after prostatectomy.

miRNA in relation to cancer constitutes an interesting field of research due to their role in gene expression regulation and because they are generally more stable than mRNA. There is however a number of conflicting results from miRNA profiling studies including irreproducible results. One major issue is the sample itself, and the tissue actually being profiled. Samples where the carcinoma cell percentage is low, will inevitably reveal a miRNA profile which is a mix the miRNAs from the carcinoma cells and the profile from the surrounding normal tissue, thus diluting the miRNA expression in the carcinoma cells. Regarding studies of aggressive PC, tumor heterogeneity has often been overlooked. Normally only a single tumor biopsy is used and the miRNA profile produced is a measurement of the miRNA expression in that given part of the tumor. If the tumor contains more aggressive clones in other parts of the prostate a discrepancy will arise between the clinical performance of the tumor and the miRNA profile obtained from the more indolent tumor cells. Another issue influencing reproducibility is the technical differences between studies. Although good reproducibility exist within RTqPCR profiling platforms, the correlation with microarray platforms is often not high, as reported by Chen et al. [26]. The number of miRNAs actually being profiled also differs between studies ranging from 119 [19] to 676 [22], in addition since different platforms are used the specificity and sensitivity of the probes detecting the miRNAs can differ leading to greater variability of the expression measurements. However, in spite of

Table 4 Univariate- and multivariate analysis of recurrence free survival in the validation cohort

\begin{tabular}{|c|c|c|c|c|c|c|}
\hline & \multicolumn{3}{|l|}{ Univariate } & \multicolumn{3}{|l|}{ Multivariate } \\
\hline & HR (95\% confidence interval) & p-value & PA \% & HR (95\% confidence interval) & p-value & PA $\%$ \\
\hline miR-449b expression & $1.57(1.05-2.37)$ & 0.028 & 0.55 & $1.90(1.25-2.85)$ & 0.003 & \\
\hline Organ confined & $2.76(1.83-4.16)$ & $<0.001$ & 0.61 & $2.57(1.66-3.07)$ & $<0.001$ & \\
\hline Gleason grade & $1.64(1.21-2.23)$ & 0.002 & 0.58 & $1.53(1.08-2.15)$ & 0.017 & \\
\hline PSA & $1.88(1.41-2.50)$ & $<0.001$ & 0.63 & $1.74(1.30-2.33)$ & $<0.001$ & \\
\hline Margin status & $1.14(1.02-1.28)$ & 0.027 & 0.62 & $1.06(0.91-1.23)$ & 0.7 & \\
\hline Age & $1.01(0.97-1.05)$ & 0.557 & 0.51 & $1.02(0.98-1.06)$ & 0.365 & \\
\hline Clinical model & & & & & & 0.69 \\
\hline Clinical model with miR-449b expression & & & & & & 0.71 \\
\hline
\end{tabular}


these challenges, several previously identified miRNAs associated with adverse characteristics in PC were also identified in our study. The miRNAs, miR-449b and miR-10b were seen previously by Fendler et al. [22], differentiating between early or late recurrence. Furthermore, several miRNAs (miR-126, miR-125-5p, miR$10 \mathrm{a} / \mathrm{b}$ ) overlapped with the miRNAs identified by Prueitt et al. [20] being associated with perineural invasion. Finally, miR-449b and miR-484 overlapped with the miRNAs associated with extraprostatic disease extension identified by Ambs et al. [16]. Among the down regulated microRNAs found in this study, miR-154 was also seen down regulated in patients with biochemical recurrence after prostatectomy by Tong et al. [19]. In addition to the microRNAs previously linked to aggressive traits in PC several new microRNAs were identified to be associated with recurrent disease.

The use of biochemical recurrence as surrogate endpoint of aggressive prostate cancer has limitations. Other end-points like time to metastasis or progression to death are stronger end-points for the clinical aggressiveness of prostate cancer, unfortunately this data was not available for the cohort. The Gleason grade included in the multivariate model of the validation cohort is based on the original pathology grading. Gleason grading has changed over time and a re-evaluation of the prostatectomy specimens would strengthen the model.

The miR-449b gene is situated on chromosome 5 in the second intron of the CDC20B gene. MiR-449b shares seed sequence with miR-449a which is also transcribed in the second intron of CDC20B. This off course implies similar mRNA targets and thus similar functions. In our study we found that miR-449a had a similar fold change difference of 3.8 compared with 3.2 for miR$449 \mathrm{~b}$ between the recurrent and non-recurrent cases, but miR-449a expression was not significantly associated with recurrence in Mann-Whitney test. This difference can be due to specificity and/or sensitivity of the PCR probes for miR-449a and miR-449b respectively.

As described above the miR-449 cluster has previously been associated with adverse outcomes in PC. In contrast to this miR-449 functional studies have provided conflicting results. The miR-449 cluster has been implicated in different cellular functions primarily in cell cycle control and in cellular differentiation [27]. MiR-449b has been shown to inhibit androgen receptor expression resulting in inhibited androgen mediated proliferation [28]. Studies using the Saos-2 osteosarcoma cell line show that mir-449 cluster transcription is inducible by the E2F1 transcription factor. Induced miR-449 has been shown to cause causes cell cycle arrest and promote apoptosis by inhibiting CDK6 and CDC25A. In this way it functions as a negative feedback mechanism against E2F1 induced cell proliferation [28]. In other studies using cell lines originating from prostate, breast and lung cancer the miR-449 cluster has also been associated with cell cycle arrest and a role as tumor suppressor although through different mechanisms [29-31]. However a different functional role of miR-449 cluster is the interaction with LEF-1 a known effector of the WNT pathway [32]. In the cell line hBM-MSC the miR-449 cluster has been shown to directly inhibit the LEF-1 gene and thus the WNT pathway. Although WNT pathway inhibition in general inhibits cancer growth, including PC, [33-35] other effects have been observed that relate to PC progression. Firstly LEF-1 inhibition has been shown to inhibit osteoblast differentiation and result in reduced bone density, a phenotype that would facilitate the establishment of PC cells in bone [36]. Secondly studies looking at the interaction between WNT signaling and androgen receptor function reveals a complex interaction with some evidence that WNT pathway signaling enhances androgen receptor signaling other evidence inhibiting androgen signaling [37]. The miR-449 cluster has also been identified targeting the NOTCH pathway thus altering cell differentiation [38]. Whereas NOTCH pathway signaling again in general is shown to induce EMT and cancer progression, NOTCH signaling is also linked to inhibiting bone formation. In this manner and like the inhibition of LEF-1, the mechanism of action for miR-449b overexpression in aggressive $\mathrm{PC}$ could be an increased propensity to metastasize to bone. Further studies are needed to investigate the functional role of miR-449 in normal and malignant prostate cells.

\section{Conclusion}

The current study identified 31 miRNAs to be associated with biochemical recurrence of prostate cancer after radical prostatectomy. The highest ranked miRNA, miR$449 \mathrm{~b}$, was further validated in an independent cohort of patients and shown to be an independent predictor of recurrence after radical prostatectomy.

\section{Competing interests}

The authors declare that they have no competing interests.

Authors' contributions

MMM, KDS, TFO, LD, MB designed the study; MB and MMM provide tumor tissue and clinical data; SH evaluated and graded the tumors; MMM and SH performed the laboratory research; MMM and LD analyzed data; MMM, MB and LD wrote the paper. All authors read and approved the final manuscript.

\section{Acknowledgements}

The project has been supported by a donation from the heritance of manufacturer Holger K. Christiansen and by funding from the University of Aarhus. The work was also supported by the John and Birthe Meyer Foundation, The Danish Cancer Society, The Danish Strategic Research Council and the Danish Advanced Technology Foundation. We thank Ms. Pamela Celis, Ms. Margaret Gellett, Ms. Birgitte Trolle and Ms. Hanne Steen for excellent technical assistance. 


\section{Author details}

${ }^{1}$ Department of Molecular Medicine, Aarhus University Hospital, Brendstrupgaardsvej 100, 8200 Aarhus N, Denmark. ²Department of Urology, Aarhus University Hospital, Brendstrupgaardsvej 100, 8200 Aarhus N Denmark. ${ }^{3}$ Department of Pathology, Aarhus University Hospital Nørrebrogade 44, 8000 Aarhus C, Denmark.

Received: 13 March 2014 Accepted: 30 October 2014

Published: 21 November 2014

\section{References}

1. Ferlay J, Shin HR, Bray F, Forman D, Mathers C, Parkin DM: Estimates of worldwide burden of cancer in 2008: GLOBOCAN 2008. Int J Cancer 2008, 2010(127):2893-2917.

2. Gosselaar C, Roobol MJ, Schroder FH: Prevalence and characteristics of screen-detected prostate carcinomas at low prostate-specific antigen levels: aggressive or insignificant? BJU Int 2005, 95:231-237.

3. Schröder FH, Hugosson J, Roobol MJ, Tammela TL, Ciatto S, Nelen V, Kwiatkowski M, Lujan M, Lilja H, Zappa M, Denis LJ, Recker F, Berenguer A, Määttänen L, Bangma CH, Aus G, Villers A, Rebillard X, van der Kwast T, Blijenberg BG, Moss SM, de Koning HJ, Auvinen A, ERSPC Investigators: Screening and prostate-cancer mortality in a randomized European study. N Engl J Med 2009, 360:1320-1328.

4. Vickers A, Bennette C, Steineck G, Adami HO, Johansson JE, Bill-Axelson A Palmgren J, Garmo H, Holmberg L: Individualized estimation of the benefit of radical prostatectomy from the Scandinavian Prostate Cancer Group randomized trial. Eur Urol 2012, 62:204-209.

5. Klotz L: Active surveillance for prostate cancer: overview and update. Curr Treat Options Oncol 2013, 14:97-108.

6. Ahmed FE: Role of miRNA in carcinogenesis and biomarker selection: a methodological view. Expert Rev Mol Diagn 2007, 7:569-603.

7. Hanahan D, Weinberg RA: The hallmarks of cancer. Cell 2000, 100:57-70.

8. Hammond SM: MicroRNAs as oncogenes. Curr Opin Genet Dev 2006, 16:4-9.

9. Kent OA, Mendell JT: A small piece in the cancer puzzle: microRNAs as tumor suppressors and oncogenes. Oncogene 2006, 25:6188-6196.

10. Garzon R, Fabbri M, Cimmino A, Calin GA, Croce CM: MicroRNA expression and function in cancer. Trends Mol Med 2006, 12:580-587.

11. Chen X, Ba Y, Ma L, Cai X, Yin Y, Wang K, Guo J, Zhang Y, Chen J, Guo X, L Q, Li X, Wang W, Zhang Y, Wang J, Jiang X, Xiang Y, Xu C, Zheng P, Zhang J, Li R, Zhang H, Shang X, Gong T, Ning G, Wang J, Zen K, Zhang J, Zhang CY: Characterization of microRNAs in serum: a novel class of biomarkers for diagnosis of cancer and other diseases. Cell Res 2008, 18:997-1006.

12. Mitchell PS, Parkin RK, Kroh EM, Fritz BR, Wyman SK, Pogosova-Agadjanyan EL, Peterson A, Noteboom J, O'Briant KC, Allen A, Lin DW, Urban N, Drescher CW, Knudsen BS, Stirewalt DL, Gentleman R, Vessella RL, Nelson PS, Martin DB, Tewari M: Circulating microRNAs as stable blood-based markers for cancer detection. Proc Natl Acad Sci U S A 2008, 105:10513-10518.

13. Bryant RJ1, Pawlowski T, Catto JW, Marsden G, Vessella RL, Rhees B, Kuslich C, Visakorpi T, Hamdy FC: Changes in circulating microRNA levels associated with prostate cancer. Br J Cancer 2012, 106:768-774

14. Brase JC, Johannes M, Schlomm T, Fälth M, Haese A, Steuber T, Beissbarth T, Kuner R, Sültmann H: Circulating miRNAs are correlated with tumor progression in prostate cancer. Int J Cancer 2011, 128:608-616.

15. Ozen M, Creighton CJ, Ozdemir M, Ittmann M: Widespread deregulation of microRNA expression in human prostate cancer. Oncogene 2008 27:1788-1793

16. Ambs S, Prueitt RL, Yi M, Hudson RS, Howe TM, Petrocca F, Wallace TA, Liu CG, Volinia S, Calin GA, Yfantis HG, Stephens RM, Croce CM: Genomic profiling of microRNA and messenger RNA reveals deregulated microRNA expression in prostate cancer. Cancer Res 2008, 68:6162-6170.

17. Porkka KP, Pfeiffer MJ, Waltering KK, Vessella RL, Tammela TL, Visakorpi T: MicroRNA expression profiling in prostate cancer. Cancer Res 2007 67:6130-6135

18. Schaefer A, Jung M, Mollenkopf HJ, Wagner I, Stephan C, Jentzmik F, Miller K, Lein $M$, Kristiansen $G$, Jung K: Diagnostic and prognostic implications of microRNA profiling in prostate carcinoma. Int J Cancer 2010, 126:1166-1176.

19. Tong AW, Fulgham P, Jay C, Chen P, Khalil I, Liu S, Senzer N, Eklund AC, Han J, Nemunaitis J: MicroRNA profile analysis of human prostate cancers. Cancer Gene Ther 2009, 16:206-216.

20. Prueitt RL, Yi M, Hudson RS, Wallace TA, Howe TM, Yfantis HG, Lee DH, Stephens RM, Liu CG, Calin GA, Croce CM, Ambs S: Expression of
microRNAs and protein-coding genes associated with perineural invasion in prostate cancer. Prostate 2008, 68:1152-1164.

21. Spahn M, Kneitz S, Scholz CJ, Stenger N, Rüdiger T, Ströbel P, Riedmiller H, Kneitz B: Expression of microRNA-221 is progressively reduced in aggressive prostate cancer and metastasis and predicts clinical recurrence. Int J Cancer 2010, 127:394-403.

22. Fendler A, Jung M, Stephan C, Honey RJ, Stewart RJ, Pace KT, Erbersdobler A, Samaan S, Jung K, Yousef GM: miRNAs can predict prostate cancer biochemical relapse and are involved in tumor progression. Int J Oncol 2011, 39:1183-1192.

23. Coppola V, De MR, Bonci D: MicroRNAs and prostate cancer. Endocr Relat Cancer 2010, 17:F1-F17.

24. Heebøll S, Borre M, Ottosen PD, Andersen CL, Mansilla F, Dyrskjøt L, Orntoft TF, Tørring N: SMARCC1 expression is upregulated in prostate cancer and positively correlated with tumour recurrence and dedifferentiation. Histol Histopathol 2008, 23:1069-1076.

25. Haldrup C, Mundbjerg K, Vestergaard EM, Lamy P, Wild P, Schulz WA, Arsov C, Visakorpi T, Borre M, Høyer S, Orntoft TF, Sørensen KD: DNA methylation signatures for prediction of biochemical recurrence after radical prostatectomy of clinically localized prostate cancer. J Clin Oncol 2013, 31:3250-3258.

26. Chen Y, Gelfond JA, McManus LM, Shireman PK: Reproducibility of quantitative RT-PCR array in miRNA expression profiling and comparison with microarray analysis. BMC Genomics 2009, 10:407.

27. Yang X, Feng M, Jiang X, Wu Z, Li Z, Aau M, Yu Q: miR-449a and miR-449b are direct transcriptional targets of E2F1 and negatively regulate pRb-E2F1 activity through a feedback loop by targeting CDK6 and CDC25A. Genes Dev 2009, 23:2388-2393.

28. Lize M, Pilarski S, Dobbelstein M: E2F1-inducible microRNA 449a/b suppresses cell proliferation and promotes apoptosis. Cell Death Differ 2010, 17:452-458

29. Noonan EJ1, Place RF, Pookot D, Basak S, Whitson JM, Hirata H, Giardina C, Dahiya R: miR-449a targets HDAC-1 and induces growth arrest in prostate cancer. Oncogene 2009, 28:1714-1724.

30. Noonan EJ, Place RF, Basak S, Pookot D, Li LC: miR-449a causes Rbdependent cell cycle arrest and senescence in prostate cancer cells. Oncotarget 2010, 1:349-358.

31. Ren XS, Yin MH, Zhang X, Wang Z, Feng SP, Wang GX, Luo YJ, Liang PZ, Yang XQ, He JX, Zhang BL: Tumor-suppressive microRNA-449a induces growth arrest and senescence by targeting E2F3 in human lung cancer cells. Cancer Lett 2013, 344:195-203.

32. Paik S, Jung HS, Lee S, Yoon DS, Park MS, Lee JW: miR-449a regulates the chondrogenesis of human mesenchymal stem cells through direct targeting of lymphoid enhancer-binding factor-1. Stem Cells Dev 2012, 21:3298-3308

33. Chesire DR, Ewing CM, Gage WR, Isaacs WB: In vitro evidence for complex modes of nuclear beta-catenin signaling during prostate growth and tumorigenesis. Oncogene 2002, 21:2679-2694.

34. Chesire DR, Ewing CM, Sauvageot J, Bova GS, Isaacs WB: Detection and analysis of beta-catenin mutations in prostate cancer. Prostate 2000, 45:223-234

35. Polakis P: Wnt signaling in cancer. Cold Spring Harb Perspect Biol 2012, 4:a008052

36. Noh T, Gabet Y, Cogan J, Shi Y, Tank A, Sasaki T, Criswell B, Dixon A, Lee C, Tam J, Kohler T, Segev E, Kockeritz L, Woodgett J, Müller R, Chai Y, Smith E, Bab I, Frenkel B: Lef1 haploinsufficient mice display a low turnover and low bone mass phenotype in a gender- and age-specific manner. PLoS One 2009, 4:e5438.

37. Terry S, Yang X, Chen MW, Vacherot F, Buttyan R: Multifaceted interaction between the androgen and Wnt signaling pathways and the implication for prostate cancer. J Cell Biochem 2006, 99:402-410.

38. Marcet B, Chevalier B, Luxardi G, Coraux C, Zaragosi LE, Cibois M, RobbeSermesant K, Jolly T, Cardinaud B, Moreilhon C, Giovannini-Chami L, NawrockiRaby B, Birembaut P, Waldmann R, Kodjabachian L, Barbry P: Control of vertebrate multiciliogenesis by miR-449 through direct repression of the Delta/Notch pathway. Nat Cell Biol 2011, 13:693-699.

doi:10.1186/1471-2407-14-859

Cite this article as: Mortensen et al:: High miR-449b expression in prostate cancer is associated with biochemical recurrence after radical prostatectomy. BMC Cancer 2014 14:859. 